\title{
Adequação do teste de tetrazólio para avaliação da qualidade de sementes de Ceiba speciosa
}

\author{
Adaptation of the tetrazolium test for evaluation \\ of Ceiba speciosa seeds
}

\author{
Marília Lazarotto $^{1 *}$; Graziela Piveta ${ }^{1}$; Marlove Fátima Brião Muniz²; Lia Rejane \\ Silveira Reiniger ${ }^{3}$
}

\begin{abstract}
Resumo
O objetivo deste estudo foi definir a metodologia mais adequada para a realização do teste de tetrazólio em sementes de Ceiba speciosa (A. St. - Hil.) Ravenna - Malvaceae (paineira). Duas amostras de sementes foram utilizadas, para as quais, inicialmente, determinaram-se o teor de água e a germinação. Para o teste de tetrazólio foram testados dois tempos de exposição, três e quatro horas, e três concentrações da solução de tetrazólio, 0,1, 0,5 e 1\%. O delineamento estatístico foi inteiramente casualizado em esquema fatorial $2 \times 2 \times 3$ (amostras $\times$ tempos x concentrações) com quatro repetições de 25 sementes. A comparação das médias foi feita pelo teste de Duncan a $5 \%$ e após foi realizada análise de correlação entre os resultados do tetrazólio e de germinação. Embora a concentração de $0,1 \%$ de tetrazólio tenha permitido a visualização de uma maior porcentagem de sementes viáveis, para ambas as amostras e ambos os tempos de exposição, apenas a concentração de $0,5 \%$ com quatro horas de exposição, se correlacionou positiva e significativamente com a germinação para ambas as amostras. Portanto, o teste de tetrazólio para sementes de paineira deve ser realizado utilizando-se para coloração a solução de tetrazólio a $0,5 \%$, por quatro horas.
\end{abstract}

Palavras-chave: Paineira, viabilidade, sementes florestais

\begin{abstract}
The nutritional state of star fruit seedlings must be adequate for a successful field implementation. The The objective of this research was to define the tetrazolium test methodology for Ceiba speciosa seeds. Two $C$. speciosa seeds samples were used and, for each of these, it were determinate the moisture content and germination. For the tetrazolium test it were tested two periods of tetrazolium solution exposition (three and four hours), and three tetrazolium solutions concentrations $(0.1,0.5$ and $1.0 \%)$. All the treatments were submitted to the temperature of $40^{\circ} \mathrm{C}$ in dark. The statistical design was completely randomized, in a factorial scheme $2 \times 2 \times 3$ (samples $\mathrm{x}$ periods $\mathrm{x}$ concentrations) with four replications of 25 seeds. The means comparison was by the Duncan test at the 0.05 level of probability and were done correlation tests between tetrazolium and germination tests. Although the tetrazolium solution $0.1 \%$ allowed identify high percentages of viable seeds for both samples and periods, only the $0.5 \%$ concentration for four hours had a positive and significant correlation with the germination for both samples. Thus, the tetrazolium test for Ceiba speciosa seeds should be realized with the tetrazolium solution concentration of $0.5 \%$, for four hours.
\end{abstract}

Key words: Ceiba speciosa, viability, forest seeds

${ }^{1}$ Eng ${ }^{\circ}$. Florestal, MSc. em Engenharia Florestal, Doutoranda do Programa de Pós-Graduação em Engenharia Florestal da Universidade Federal de Santa Maria, UFSM. Dept ${ }^{0}$ de Defesa Fitossanitária/CCR/UFSM, CEP: 97105-900. E-mail: lilalazarotto@yahoo.com.br; grazipiveta@yahoo.com.br

2 Eng $^{\mathrm{o}}$ Agr $^{\circ}$, Dr. Prof. Adjunto do Dept ${ }^{\circ}$ de Defesa Fitossanitária/CCR/UFSM. E-mail: marlovemuniz@yahoo.com.br

3 Eng $^{\mathrm{o}} \mathrm{Agr}^{\mathrm{o}}$, Dr. Prof. Adjunto do Dept ${ }^{\circ}$ de Fitotecnia/CCR/UFSM. E-mail: liarejanesilveirareiniger@yahoo.com.br

* Autor para correspondência

Recebido para publicação 22/03/2010 Aprovado em 11/02/2011 


\section{Introdução}

Espécie arbórea de grande porte, pertencente à família Malvaceae, a paineira (Ceiba speciosa (A. St. - Hil.) Ravenna) pode alcançar entre 15 a 30 metros de altura. Esta espécie possui grande importância ecológica, sendo utilizada para recuperação de áreas úmidas, já que suporta esta condição, e para alimentação da fauna silvestre, pois suas folhas fazem parte da alimentação do macaco bugio (Aloatta fusca). Além disso, é recomendada em plantios para reconstituição de matas e recuperação de mata ciliar em locais sem inundação (CARVALHO, 2003).

A produção de mudas de paineira deve ser feita com a utilização de sementes sadias e vigorosas, entretanto, a disponibilidade de sementes é baixa, o que justifica o tratamento e armazenamento destas (SILVA et al., 2003).

As sementes desta espécie são classificadas como ortodoxas, isto é, se mantêm viáveis após dessecação até um grau de umidade em torno de $5 \%$ e podem ser armazenadas sob baixas temperaturas por um longo período (CARVALHO; SILVA; DAVIDE, 2006). Entretanto, a germinação é irregular ficando entre 30 a 100\% (CARVALHO, 2003). As baixas percentagens de germinação desta espécie podem estar associadas aos danos causados por insetos e fungos, danos durante a coleta ou mesmo por problemas no armazenamento.

$\mathrm{O}$ uso de testes mais rápidos, visando fornecer ao produtor ou viveirista uma informação precisa quanto ao desempenho na semeadura, tem sido uma estratégia dos comerciantes que estão mais hábeis na produção de sementes (MENDONÇA; RAMOS; PAULA, 2001). Entre os testes rápidos, destaca-se o teste do tetrazólio, o qual possui algumas vantagens em relação ao teste de germinação, tais como o fato de não ser afetado por microrganismos e de fornecer o diagnóstico da causa da redução da viabilidade das sementes (FRANÇA NETO, 1999).

O teste de tetrazólio reflete a atividade das enzimas desidrogenases, envolvidas no processo de respiração. Pela hidrogenação do 2, 3, 5 trifenil cloreto de tetrazólio, é produzida, nas células vivas, uma substância vermelha, estável e não difusível, o trifenil formazan. Isto torna possível distinguir as partes vivas, coloridas de vermelho, daquelas mortas que não colorem (OLIVEIRA; CARVALHO; DAVIDE, 2005). Em sementes de espécies perenes, como as essências florestais e frutíferas, sua utilização é pouco difundida, embora apresente um grande potencial para ser rotineiramente adotado, uma vez que, muitas dessas espécies necessitam de um longo período para germinar (PIÑARODRIGUES; SANTOS, 1988).

Segundo Brasil (2009), dentre algumas das aplicações do teste de tetrazólio está a avaliação de vigor, viabilidade de sementes após-tratamentos pré-germinativos, e para algumas espécies é possível observar os danos por secagem, por insetos e por umidade e também detectar danos mecânicos ocorridos durante a colheita e/ou beneficiamento.

Para Gaspar-Oliveira, Martins e Nakagawa (2009) diversos fatores podem interferir na obtenção de resultados satisfatórios no teste de tetrazólio, principalmente aqueles relacionados à metodologia de execução como preparo das sementes antes da coloração, concentração da solução de tetrazólio, período e temperatura de exposição à solução e critérios de interpretação. Entre os procedimentos para preparação das sementes, antes da realização do teste de tetrazólio, está o pré-condicionamento que, segundo Vieira e Von Pinho (1999), amolece a semente e facilita a penetração da solução do tetrazólio; e ainda podem ser citados a punção, o corte e a retirada do tegumento (NERY; CARVALHO; OLIVEIRA, 2007). O tempo necessário para que a coloração adequada se desenvolva, varia com a espécie, ficando entre 30 e 240 minutos (KRZYZANOWSKI; VIEIRA; FRANCA NETO, 1999).

Apesar das informações rápidas e precisas sobre a viabilidade de um lote de sementes que o teste de tetrazólio é capaz de fornecer, nas Regras 
para Análises de Sementes (BRASIL, 2009) a metodologia padronizada para espécies florestais se restringe, basicamente, para espécies exóticas, especialmente gimnospermas. Porém, há uma preocupação por parte dos pesquisadores com o ajuste das avaliações de sementes florestais nativas. Assim, trabalhos com teste de tetrazólio vem sendo realizados para que se possa tomá-los como referência em estudos posteriores, tais como os realizados por Mendes, Bastos e Melo (2009), Oliveira, Carvalho e Davide (2005), Fogaça et al. (2006), Zucareli et al. (2001), Pinto et al. (2008) e Cherobini (2006).

Diante do exposto, este trabalho teve como objetivo definir a metodologia mais adequada para a condução do teste de tetrazólio em sementes de Ceiba speciosa.

\section{Material e Métodos}

Duas amostras de sementes de paineira foram utilizadas: Amostra 1 - coletada no município de Venâncio Aires (RS) em agosto de 2006; e Amostra 2 - coletada em Nova Prata do Iguaçu (PR) em 2006. Ambas estavam armazenadas em câmara fria $\left(5-10^{\circ} \mathrm{C}\right)$, sob baixa umidade, antes da realização dos testes.

Teor de água das sementes: foram utilizadas 80 sementes, divididas em quatro repetições de 20 sementes. Estas foram inicialmente colocadas em placas de petri e pesadas para verificação da massa úmida. Posteriormente, estas sementes foram colocadas em estufa à $105^{\circ} \mathrm{C} \pm 2{ }^{\circ} \mathrm{C}$ por 24 horas. Após as 24 horas na estufa, as sementes foram novamente pesadas, juntamente com as placas de petri, para verificação da massa seca e cálculo do teor de água com base na massa úmida (BRASIL, 2009).

Teste de germinação: inicialmente, as sementes foram imersas, por duas horas, em água fria (temperatura ambiente), conforme recomendado por Carvalho (2003), para facilitar a germinação desta espécie. Foram utilizadas 200 sementes, divididas em quatro repetições (FANTI; PEREZ, 2005), distribuídas em caixas de plástico transparente (gerbox) previamente desinfestadas com solução de hipoclorito de sódio a $1 \%$, com duas folhas de papel-filtro esterilizadas e umedecidas com água destilada esterilizada na proporção de 2,5 vezes a massa do papel seco. As sementes foram desinfestadas em álcool a $70 \%$ (30 segundos), depois em hipoclorito de sódio a 1\% (2 minutos) e, em seguida, lavadas em água estéril para retirada do excesso dos produtos utilizados na desinfestação. As caixas plásticas foram mantidas em câmara com temperatura de $25^{\circ} \mathrm{C}$ e fotoperíodo de 12 horas sob luz branca. A avaliação da primeira contagem de germinação foi realizada aos sete dias a partir da instalação do teste, e a germinação aos 14 dias. $\mathrm{Na}$ primeira contagem, quantificaram-se apenas as plântulas normais, e na segunda, plântulas normais, anormais, sementes duras e mortas.

Teste do tetrazólio: após alguns testes preliminares verificou-se que o pré-condicionamento das sementes por 8 horas, com imersão em água à temperatura ambiente foi suficiente para que o corte das sementes fosse realizado com o mínimo de danos possível. Após o pré-condicionamento, fezse o corte longitudinal, exatamente pela metade da semente, descartando-se uma das partes para, após, colocar a parte restante para coloração (GRABE, 1976). Utilizou-se 100 sementes, divididas em quatro repetições de 25. Considerou-se como tratamentos dois tempos de exposição, 3 e 4 horas, e três concentrações de tetrazólio, $0,1,0,5$ e $1 \%$. Todos os tratamentos foram submetidos a $40^{\circ} \mathrm{C}$ em estufa e na ausência de luz. Após cada combinação de tempo de coloração e concentração de tetrazólio estudados, as sementes foram observadas individualmente através de lupa e classificadas em seis categorias, sendo duas de sementes viáveis e quatro de inviáveis, como segue: Categoria 1 (viável): embrião com coloração rosa e tecidos com aspecto normal e firme, Categoria 2 (viável): menos de $50 \%$ dos cotilédones descoloridos, embrião 
rosado e intacto e os demais tecido firmes, Categoria 3 (inviável): embrião colorido, porém mais de $50 \%$ dos tecidos esbranquiçados e não firmes, Categoria 4 (inviável): semente com tecidos esbranquiçados, inclusive o embrião, Categoria 5 (inviável): embrião vermelho intenso ou com regiões brancas e Categoria 6 (inviável): todos os tecidos coloridos de um vermelho intenso (Figura 1).

Figura 1. Categorias de sementes de Ceiba speciosa submetidas ao teste de tetrazólio.

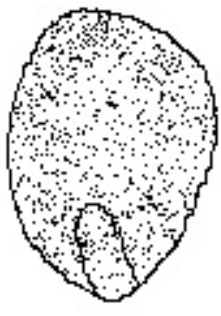

1

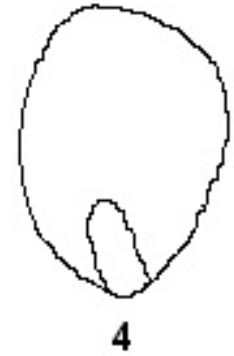

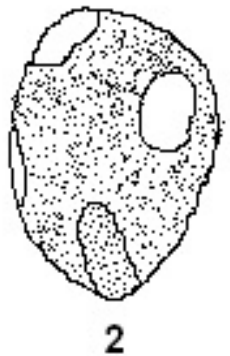

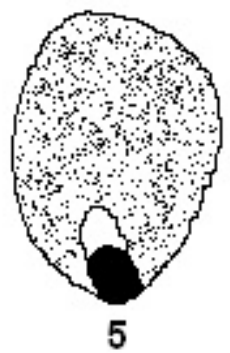

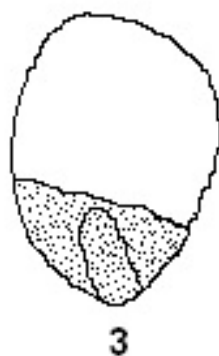

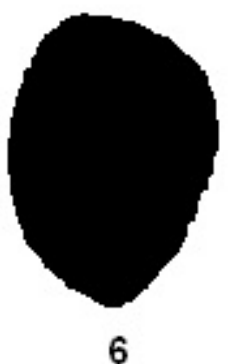

6

$\square$ Descolorida

2.: Vermelho normal

Vermelho intenso

Análise estatística: o delineamento experimental utilizado foi inteiramente casualizado em esquema fatorial $2 \times 2 \times 3$ (amostras $\times$ tempos $\times$ concentrações) com quatro repetições de 25 sementes. Para a análise de variância, os dados obtidos foram transformados segundo arc sen $\sqrt{x} / 100$. A comparação das médias foi feita pelo teste de Duncan a 5\% de probabilidade. Para a correlação linear utilizou-se o teste t.

\section{Resultados e Discussão}

As amostras de sementes de paineira, Amostra
1 - coletada em Venâncio Aires (RS) e Amostra 2 - coletada em Nova Prata do Iguaçu (PR), apresentaram teor de água em torno de $11,8 \%$ e $15,5 \%$, respectivamente. Carvalho, Silva e Davide (2006) encontraram teor de água de 18,8\% em sementes recém-beneficiadas de paineira e 8,3\% após secagem. Para Medeiros (2001), teores de água abaixo de $13 \%$ não comprometem a qualidade das sementes, permitindo seu armazenamento por maiores períodos, portanto, somente a Amostra 2 ultrapassou este limite adequado. 
$\mathrm{Na}$ (Tabela 1) estão apresentados os resultados do teste de germinação para ambas as amostras de paineira utilizadas. A amostra de Nova Prata do Iguaçu (Amostra 2), além de ter menor percentual de sementes germinadas na primeira contagem e menor germinação que a amostra de Venâncio Aires (Amostra 1), apresentou uma alta porcentagem de sementes mortas, indicando ser a Amostra 2 a de menor qualidade fisiológica. Porém, a Amostra 1 apresentou maior percentagem de plântulas anormais, que pode ser devido à fatores genéticos, como endogamia, ou a presença de micro-organismos deterioradores que impedem seu desenvolvimento normal.

Tabela 1. Resultados médios (\%) de plântulas normais referentes a primeira contagem do teste de germinação (PCG) e ao teste de germinação e plântulas anormais, sementes duras e mortas para duas amostras de sementes de paineira.

\begin{tabular}{llcccc}
\hline Amostras & \multicolumn{5}{c}{ Variáveis } \\
\cline { 2 - 6 } & PCG & Germinação & Anormais & Duras & Mortas \\
\hline Amostra 1 & $44 \mathrm{a} *$ & $62 \mathrm{a}$ & $16 \mathrm{a}$ & $12 \mathrm{a}$ & $10 \mathrm{~b}$ \\
Amostra 2 & $27 \mathrm{~b}$ & $44 \mathrm{~b}$ & $4 \mathrm{~b}$ & $10 \mathrm{a}$ & $42 \mathrm{a}$ \\
CV (\%) & 4,2 & 7,8 & 10,1 & 2,4 & 14,7
\end{tabular}

* Médias seguidas de letras iguais, na coluna, não diferem entre si, pelo teste de Duncan ao nível de $5 \%$ de probabilidade. Sendo: Amostra 1 - Venâncio Aires - RS (2006), e Amostra 2 - Nova Prata do Iguaçu - PR (2006).

Os resultados inferiores da germinação da Amostra 2 podem estar relacionados ao teor de água superior desta amostra, o qual pode ter prejudicado o armazenamento das sementes, já que estas estavam armazenadas há três anos por ocasião da realização dos testes de germinação. Além disso, as sementes mortas podem ser resultados da associação das sementes com fungos de armazenamento, os quais não foram totalmente eliminados pela desinfestação superficial, que reduzem a germinação das sementes.

No teste de tetrazólio, a análise de variância indicou interações significativas entre tempos de exposição e concentrações do tetrazólio e não significativa entre amostras. Deste modo, na (Tabela 2), pode-se observar os resultados para sementes viáveis, soma das categorias 1 e 2, para a combinação de diferentes concentrações e tempos de exposição ao sal de tetrazólio.

Tabela 2. Dados médios (\%) de sementes viáveis (soma das médias das categorias 1 e 2) de paineira para as três concentrações de sal de tetrazólio e dois tempos de exposição testados.

\begin{tabular}{lllll}
\hline Concentrações & \multicolumn{4}{c}{ Tempos de exposição } \\
\cline { 2 - 5 } & \multicolumn{3}{c}{ Amostra 1 } & \multicolumn{2}{c}{ Amostra 2 } \\
\cline { 2 - 5 } & 3 horas & 4 horas & 3 horas & 4 horas \\
\hline $0,1 \%$ & $57 \mathrm{~A} * \mathrm{~B}$ & $50 \mathrm{Aa}$ & $55 \mathrm{Aa}$ \\
$0,5 \%$ & $47 \mathrm{C} \mathrm{b}$ & $60 \mathrm{~A} \mathrm{a}$ & $43 \mathrm{Ba}$ & $42 \mathrm{Ba}$ \\
$1,0 \%$ & $51 \mathrm{~B} \mathrm{a}$ & $46 \mathrm{C} \mathrm{b}$ & $34 \mathrm{Ca}$ & $37 \mathrm{Ca}$ \\
\hline
\end{tabular}

* Médias seguidas de letras iguais, maiúsculas nas colunas e minúsculas nas linhas, não diferem entre si, pelo teste de Duncan ao nível de 5\% de probabilidade. Sendo: Amostra 1 - Venâncio Aires - RS (2006), e Amostra 2 - Nova Prata do Iguaçu - PR (2006). 
$\mathrm{Na}$ Amostra 1, as diferenças entre os tempos de exposição ocorreram somente para as concentrações de $1 \%$ e $0,5 \%$. Para o tempo de exposição de três horas, a concentração de $0,1 \%$ de sal de tetrazólio foi a que permitiu visualizar a maior percentagem de sementes viáveis, já no tempo de quatro horas, a concentração de $0,5 \%$ resultou em média significativamente superior para esta variável. Para a Amostra 2, não houve diferenças entre os tempos de exposição, três e quatro horas, em nenhuma das concentrações de tetrazólio. As diferenças ocorreram entre concentrações, sendo que a $0,1 \%$ foi a que permitiu a visualização da maior parte das sementes viáveis, como ocorreu para a Amostra 1, seguida de $0,5 \%$ e $1 \%$.
Para Krzyzanowski, Vieira e Franca Neto (1999), a escolha de metodologia adequada para o emprego do teste de tetrazólio deve se basear na facilidade para a diferenciação de tecidos viáveis e inviáveis e na capacidade de diferenciar lotes de qualidade fisiológica distintas. Além disso, o teste de tetrazólio deve representar o teste de germinação, ou seja, fornecer uma ideia aproximada da germinação de determinado lote de sementes. Por isso, na (Tabela 3) estão apresentados os coeficientes de correlação linear entre as plântulas normais do teste de germinação e as sementes viáveis observadas no teste de tetrazólio.

Tabela 3. Coeficientes de correlação simples (r) entre o teste de germinação e as sementes viáveis (soma das médias das categorias 1 e 2) do teste de tetrazólio para duas amostras de sementes de paineira.

\begin{tabular}{lccccc}
\hline & Amostra 1 & \multicolumn{3}{c}{ Amostra 2 } \\
\hline Tempos & Concentrações & $\mathbf{r}$ & Tempos & Concentrações & r \\
\hline 3 horas & $0,1 \%$ & $0.7248^{\mathrm{ns}}$ & 3 horas & $0,1 \%$ & $-0.8087^{\mathrm{ns}}$ \\
& $0,5 \%$ & $-0.3490^{\mathrm{ns}}$ & & $0,5 \%$ & $0.0839^{\mathrm{ns}}$ \\
& $1,0 \%$ & $0.0811^{\mathrm{ns}}$ & & $1,0 \%$ & $-0.0697^{\mathrm{ns}}$ \\
\hline 4 horas & $0,1 \%$ & $0.8200^{\mathrm{ns}}$ & 4 horas & $0,1 \%$ & $0.5200^{\mathrm{ns}}$ \\
& $0,5 \%$ & $0.9838^{* *}$ & & $0,5 \%$ & $0.8642^{* *}$ \\
& $1,0 \%$ & $0.3491^{\mathrm{ns}}$ & & $1,0 \%$ & $0,8705^{* *}$ \\
\hline
\end{tabular}

** Valor significativo a 5\% de probabilidade, ns valor não significativo a 5\% de probabilidade. Sendo: A1 - Amostra de Venâncio Aires - RS (2006), e A2 - Amostra de Nova Prata do Iguaçu - PR (2006).

Apesar da concentração $0,1 \%$ com tempo de exposição de três horas e da concentração de $0,5 \%$ por quatro horas terem demonstrado superioridade na detecção de sementes viáveis, para a Amostra 1 (Tabela 1) somente a segunda obteve correlação positiva e altamente significativa com o teste de germinação. Já para a Amostra 2, somente as concentrações de $0,5 \%$ e $1 \%$ com tempo de exposição de quatro horas se correlacionaram positiva e significativamente com as variáveis plântulas normais do teste de germinação.

Como a concentração de $0,5 \%$ de tetrazólio no tempo de exposição de quatro horas se correlacionou com a germinação para ambas as amostras, esta metodologia pode ser sugerida para a condução do teste de tetrazólio em sementes de paineira. Outros trabalhos testando metodologias para o teste de tetrazólio em sementes florestais também já foram realizados. Um exemplo é o trabalho de Mendes, Bastos e Melo (2009), com sementes de corezeiro ou visgueiro (Parkia velutina), no qual as mesmas concentrações de sal de tetrazólio do presente estudo foram testadas, que concluiu que, da mesma forma que o presente estudo, a concentração de $0,5 \%$ 
por duas horas na temperatura de $40^{\circ} \mathrm{C}$ foi a mais adequada na avaliação da viabilidade das sementes da espécie.

Estudos, testando concentrações diferentes daquelas usadas no presente trabalho, foram realizados por Oliveira, Carvalho e Davide (2005) com sementes de canafístula (Peltophorum dubium), no qual constatou que o ideal para a espécie é o uso da concentração $0,1 \%$ da solução de tetrazólio por 150 minutos a $25^{\circ} \mathrm{C}$; e de Fogaça et al. (2006) com sementes de sucará (Gleditschia amorphoides) utilizando solução a $0,075 \%$ por 3 horas; de Zucareli et al. (2001) com sementes de farinha-seca (Albizia hasslerii) onde a solução de tetrazólio com concentração de $0,1 \%$ por 5 horas de coloração, mostrou-se como alternativa viável na avaliação da viabilidade; Pinto et al. (2008), com sementes de Poecylanthe parviflora - coração-denegro, no qual foi verificado que a concentração de $0,075 \%$ de tetrazólio durante 90 minutos a $40^{\circ} \mathrm{C}$, no escuro, é a metodologia mais adequada para o emprego do teste de tetrazólio nesta espécie; e ainda de Cherobini (2006) que estudou a metodologia para a avaliação da viabilidade de sementes de timbaúva - Enterolobium contortisiliquum e guapuruvu - Schyzolobium parahyba pelo teste de tetrazólio e verificou que o mais adequado é o uso da concentração de $0,1 \%$ de tetrazólio sob temperatura de $30^{\circ} \mathrm{C}$ por 3 horas e $0,2 \%$ a $30^{\circ} \mathrm{C}$ por 2 horas e 30 minutos respectivamente para cada uma das espécies.

\section{Conclusão}

O teste de tetrazólio para sementes de paineira deve ser realizado utilizando-se para coloração a solução de tetrazólio a $0,5 \%$, por quatro horas a $40^{\circ} \mathrm{C}$ na ausência de luz.

\section{Agradecimentos}

À Bolsa de Sementes do Viveiro Florestal da UFSM, que é parte do Projeto Verdeé Vida organizado e patrocinado pela AFUBRA - Associação de Fumicultores do Brasil e ao Banco de Sementes da Embrapa Florestas pela disponibilização das sementes para realização da presente pesquisa.

\section{Referências}

BRASIL. Ministério da Agricultura, Pecuária e Abastecimento. Regras para análise de sementes. Ministério da Agricultura, Pecuária e Abastecimento. Secretaria de Defesa Agropecuária. Brasília, DF: MAPA/ ACS, 2009. 395 p.

CARVALHO, L. R.; SILVA, E. A. A.; DAVIDE, A. C. Classificação de sementes florestais quanto ao comportamento no armazenamento. Revista Brasileira de Sementes, Brasília, v. 28, n. 2, p. 15-25, 2006.

CARVALHO, P. E. R. Espécies arbóreas brasileiras. Brasília: Embrapa Informação Tecnológica; Colombo: Embrapa Florestas. 2003. 1039 p.

CHEROBINI, E. A. I. Avaliação da qualidade de sementes e mudas de espécies florestais nativas. 2006. Dissertação (Mestrado em Engenharia Florestal) Universidade Federal de Santa Maria, Santa Maria.

FANTI, S. C.; PEREZ, S. C. J. G. A. Efeitos do envelhecimento precoce no vigor de sementes de Chorisia speciosa - Bombacaceae. Revista Árvore, Viçosa, v. 29, n. 3, p. 345-352, 2005.

FOGAÇA, C. A.; MALAVASI, M. M.; ZUCARELI, C.; LMALAVASI, U. C. Aplicação do teste de tetrazólio em sementes de Gleditschia amorphoides Taub. Caesalpiniaceae. Revista Brasileira de Sementes, Brasília, v. 28, n. 3, p. 101-107, 2006.

FRANÇA NETO, J. B. Testes de tetrazólio para determinação do vigor de sementes. In: KRZYZANOWSKI, F.; VIEIRA, R. D.; FRANCA NETO, J. B. (Ed.). Vigor de sementes: conceitos e testes. Londrina: ABRATES, 1999.

GASPAR-OLIVEIRA, C. M.; MARTINS, C. T.; NAKAGAWA, J. Método de preparo das sementes de mamoneira (Ricinus communis L.) para o teste de tetrazólio. Revista Brasileira de Sementes, Brasília, v. 31, n. 1, p. 160-167, 2009.

GRABE, D. F. Manual do teste de tetrazólio em sementes. Brasília: AGIPLAN, 1976. 85 p.

KRZYZANOWSKI, F.; VIEIRA, R. D.; FRANCA NETO, J. B. (Ed.). Vigor de sementes: conceitos e testes. Londrina: ABRATES, 1999.

MEDEIROS, A. C. S. Armazenamento de sementes de 
espécies florestais nativas. Colombo: Embrapa Florestas, 2001. 24 p. (Documentos, 66).

MENDES, A. M. S.; BASTOS, A. A.; MELO, M. G. G. Padronização do teste de tetrazólio em sementes de Parkia velutina Benoist (Leguminosae - Mimosoideae). Acta Amazônica, Manaus, v. 39, n. 4, p. 823-828, 2009.

MENDONÇA, E. A. F.; RAMOS, N. P.; PAULA, R. C. Viabilidade de sementes de Cordia trichotoma (Vellozo) Arrabida ex Steudel (louro - pardo) pelo teste de tetrazólio. Revista Brasileira de Sementes, Brasília, v. 23, n. 2, p. 64-71, 2001.

NERY, M. C.; CARVALHO, M. L. M.; OLIVEIRA, L. M. Teste de tetrazólio para avaliação da qualidade fisiológica de sementes de melancia. Semina: Ciências Agrárias, Londrina, v. 28, n. 3, p. 365-372, jul./set. 2007.

OLIVEIRA, L. M.; CARVALHO, M. L. M.; DAVIDE, A. C. Teste de tetrazólio para avaliação da qualidade de sementes de Peltophorum dubium (Sprengel) TaubertLeguminosae Caesalpinioideae. Cerne, Lavras, v. 11, n. 2, p. 159-166, abr./jun. 2005.

PIÑA-RODRIGUES, F. C. M.; SANTOS, N. R. F. Teste de tetrazólio. In: PIÑA-RODRIGUES, F. C. M. (Coord.). Manual de análise de sementes florestais. Campinas: Fundação Cargill, 1988. p. 91-100.

PINTO, T. L. F.; BRANCALION, P. H. S.; NOVEMBRE, A. D. L. C.; CICERO, S. M. Avaliação da viabilidade de sementes de coração-de- negro (Poecilanthe parviflora BENTH. - FABACEAE-FABOIDEAE) pelo teste de tetrazólio. Revista Brasileira de Sementes, Brasília, v. 30, n. 1, p. 208-214, 2008.

SILVA, R. T. S. da; HOMECHIN, M.; FONSECA, E. D.; SANTIAGO, D. C. Tratamento de sementes e armazenamento na sanidade de sementes de paineira (Chorisia speciosa St. Hil). Semina: Ciências Agrárias, Londrina, v. 24, n. 2, p. 255-260, jul./dez. 2003.

VIEIRA, M. G. G. C.; VON PINHO, E. V. R. Metodologia do teste de tetrazólio em sementes de algodão. In: KRZYZANOWSKI, F. C.; VIEIRA, R. D.; FRANÇANETO, J. B. (Ed.). Vigor de sementes: conceitos e testes. Londrina: ABRATES, 1999. p. 1-13.

ZUCARELI, C.; MALAVASI, M. M.; FOGAÇA, C. A.; MALAVASI, U. C. Preparo e coloração de sementes de farinha seca (Albizia hasslerii (Chodat) Burr.) para o teste de tetrazólio. Revista Brasileira de Sementes, Brasília, v. 23, n. 2, p.186-191, 2001. 